\title{
Study on Influence Laws of Strata Behaviors for Shallow Coal Seam Mining beneath Gully Terrain
}

\author{
Zhiqiang Wang, ${ }^{1,2,3,4}$ Jingkai Li $\mathbb{D}^{1},{ }^{1}$ Chao Wu, ${ }^{1}$ Wenyu Lv, ${ }^{2}$ Jiao Zhang, ${ }^{1}$ Peng Wang, \\ Zhen $\mathrm{Li}^{5}{ }^{5}$ and Hengzhe $\mathbf{Q u}^{5}$ \\ ${ }^{1}$ School of Energy and Mining Engineering, China University of Mining and Technology (Beijing), Beijing 100083, China \\ ${ }^{2}$ State Key Laboratory of Coal Resources in Western China, Xi'an University of Science and Technology, Xi'an 710054, China \\ ${ }^{3}$ Beijing Key Laboratory for Precise Mining of Intergrown Energy and Resources, \\ China University of Mining and Technology (Beijing), Beijing 100083, China \\ ${ }^{4}$ National Demonstration Center for Experimental Safe Coal Mining and Geological Guarantee Education, \\ China University of Mining and Technology (Beijing), Beijing 100083, China \\ ${ }^{5}$ General Technology Group Engineering Design Co., Ltd., Jinan 250031, China
}

Correspondence should be addressed to Jingkai Li; jingkai0801@163.com

Received 27 May 2021; Accepted 24 June 2021; Published 2 July 2021

Academic Editor: Xuepeng Zhang

Copyright (c) 2021 Zhiqiang Wang et al. This is an open access article distributed under the Creative Commons Attribution License, which permits unrestricted use, distribution, and reproduction in any medium, provided the original work is properly cited.

\begin{abstract}
The study on influence laws of strata behaviors is the basic guarantee of safety mining for shallow coal seam beneath gully terrain. Taking 3302 mining face of Zhujiamao Coal Mine as the engineering background, the laws of strata behaviors for shallow coal seam mining beneath gully terrain are studied by field detection, theoretical analysis, and numerical simulation. The strata pressure observation and the hydraulic support working resistance show that the dynamic strata behaviors appear violently during mining beneath the gully bottom. The theoretical analysis shows that the rotation and breaking of key stratum beneath gully bottom under nonuniform load is the fundamental cause of strong dynamic strata behaviors. The numerical simulation of overburden movement and fissure development characteristics shows that the strata behaviors beneath the gully bottom are stronger than the strata behaviors beneath other areas. Additionally, according to the laws of dynamic strata behaviors, the safety measures for mining beneath gully bottom are put forward.
\end{abstract}

\section{Introduction}

In China, the coal in the eastern region has been nearly mined out, and the coal mining has been transferred to the western region, which is rich in coal reserves and has become a new energy base [1-4]. Compared with the eastern region, the coal seams in the western region are mostly shallow coal seams beneath gully terrain $[5,6]$. The characteristics of shallow coal seams beneath gully terrain are different from those of conventional coal seams [7-14]. Therefore, it is necessary to study the influence laws of strata behaviors for shallow coal seam mining beneath gully terrain.

Based on the previous research results, most of the roof overburden in shallow coal seam have only one key stratum, and a few have two key strata $[15,16]$. When key stratum is single in the overburden, the roof breaks to form a "step voussoir beam" and sinks in the shape of steps. There are only caving zone and fissure zone in overburden, but no bending zone [17]. When key strata are double in the overburden, the breakage of the main key stratum and the sub-key-stratum leads to two periodic weightings. The roof sinks in the shape of steps during the process of the major periodic weighting. Concomitantly, there are complete "three zones" in the overburden [18]. Based on the above characteristics, it can be found that although the buried depth is shallow, the strata behaviors do not alleviate during mining. Contrarily, the strata behaviors become more intense, which brings a series of difficulties to the mine 
production [19-21]. On the one hand, the prop of hydraulic support shrinks sharply in a short time under the impact of dynamic load caused by roof sliding and breaking [22]. On the other hand, the roof sinks in the shape of steps and causes many cracks on the surface after the coal seam is mined out, which has a great adverse impact on the ecological environment [23]. Simultaneously, the subsidence of the roof makes the water-conducting fracture zone connect with the aquifer as well, which is easy to cause water inrush [24]. Additionally, the lower mining face may be affected by the overlying goaf during the close-distance seam group mining. If the overlying rock fissures caused by mining in the lower face develop to the overlying goaf, it may bring many potential safety hazards. For example, the accumulated water in the overlying goaf and the harmful gas produced after spontaneous combustion of residual coal may be discharged to the lower face through the fissures [25-27]. Furthermore, if there are residual coal pillars in the overlying goaf, the lower face may show strong strata behaviors due to high stress concentration during mining beneath the overlying coal pillars $[28,29]$. In order to solve the above technical problems, for shallow coal seam, the identification method of key strata has been modified [30], the mechanical model of stope roof has been established [31], the concept of water retaining mining has been put forward [32], the development law of "three zones" has been studied [33], and the safety mining technology of close-distance seam group has been explored [34]. These research results provide a strong guarantee for the safe and efficient mining of shallow coal seam [35].

In addition to the above typical characteristics, the particularity of shallow coal seam in western region is that there are many gullies on the surface [36-38]. During mining beneath gully terrain for shallow coal seam, the dynamic strata behaviors appear violently [39-42]. For example, the roof collapses in large area, the hydraulic supports are damaged, and the overlying rock fissures extend to the surface, which seriously restricts the safe and efficient mining. In order to provide theoretical basis and technical support for shallow coal seam mining beneath gully terrain, this paper studies the mechanism and laws of strata behaviors on the basis of previous research achievements.

The field engineering example applied in this paper is the shallow coal seam beneath gully terrain in Zhujiamao Coal Mine. Firstly, the strata pressure observation and the hydraulic support working resistance detection are carried out in the field to determine the characteristics of strata behaviors. Then, the mechanism of strata behaviors is analyzed theoretically. Furthermore, the numerical experiment is applied to simulate the overburden movement and fissure development characteristics. Additionally, the safety measures for shallow coal seam mining beneath gully bottom are put forward.

\section{Study Site}

As presented in Figure 1, Zhujiamao Coal Mine is located in Yulin mining area, Shaanxi Province, China. Yulin mining area is rich in coal resources, with shallow coal seam and simple geological structure, which is conducive to large-scale mining. However, the mining area is located in the transitional zone between the southern edge of Maowusu Desert and the Loess Plateau. The mining area is a typical gully terrain with sparse vegetation, serious soil erosion, and uneven surface, which increases the difficulty of mining.

Zhujiamao Coal Mine mainly mines No. 3 coal seam; 3302 mining face is the second face in No. 3 panel. 3302 mining face is a typical shallow seam face beneath gully terrain, with buried depth of $125 \sim 248 \mathrm{~m}$ (the average buried depth is $223 \mathrm{~m}$ ). The ground surface in the mining area of 3302 face is distributed with gullies. Among them, there is a gully with the height drop of $50 \mathrm{~m}$ along the strike, which is the largest gully in this area. The dynamic strata behaviors appear strongly during mining beneath this big gully. Therefore, 3302 mining face is selected as the detection site to explore the strata behaviors laws for shallow coal seam mining beneath gully terrain, which can provide the basis for safety mining under similar conditions.

\section{Field Detection}

3.1. Macroscopic Strata Behaviors. The dynamic strata behaviors appear violently in 3302 mining face during mining beneath the gully with the height drop of $50 \mathrm{~m}$. However, the observation of strata pressure shows that the attitude of terrain has obvious influence on the strata behaviors. The strata behaviors are slight during mining beneath the downslope and upslope sections, while they are strong beneath the gully bottom. As presented in Figure 2(a), with the face advancing along the strike direction, the surface sinks in the shape of steps with the height drop of 1-2 m during mining beneath the gully bottom. Meanwhile, the surface landslides and collapses on a large scale, and a large number of mining cracks are generated, with the maximum opening width reaching $0.8 \mathrm{~m}$, which affects the surface ecological environment seriously. Similarly, as presented in Figure 2(b), the dynamic load leads to the serious subsidence of roof and severe spalling of rib in the rail crossheading. Furthermore, as presented in Figure 2(c), the hydraulic support continues to drop with the dull noise due to the impact of dynamic load. More seriously, a number of hydraulic supports are damaged and can no longer provide effective working resistance. Additionally, the roof gangue leaks from the place ahead of the hydraulic support and accumulates in the scraper conveyor rapidly machine stoppage.

3.2. Working Resistance of Hydraulic Support. Obviously, the strata behaviors are the strongest during mining beneath the gully bottom according to the above observation. In order to accurately predict the laws of the strata behaviors and the position of the pressure in the mining face, the working resistance of the hydraulic support is detected in real time by applying the roof online monitoring system. As presented in Table 1 and Figure 3, 29 stations are arranged in 3302 mining face, of which 1 to 11 stations form the upper section, 12 to 21 stations form the middle section, and 22 to 29 stations 


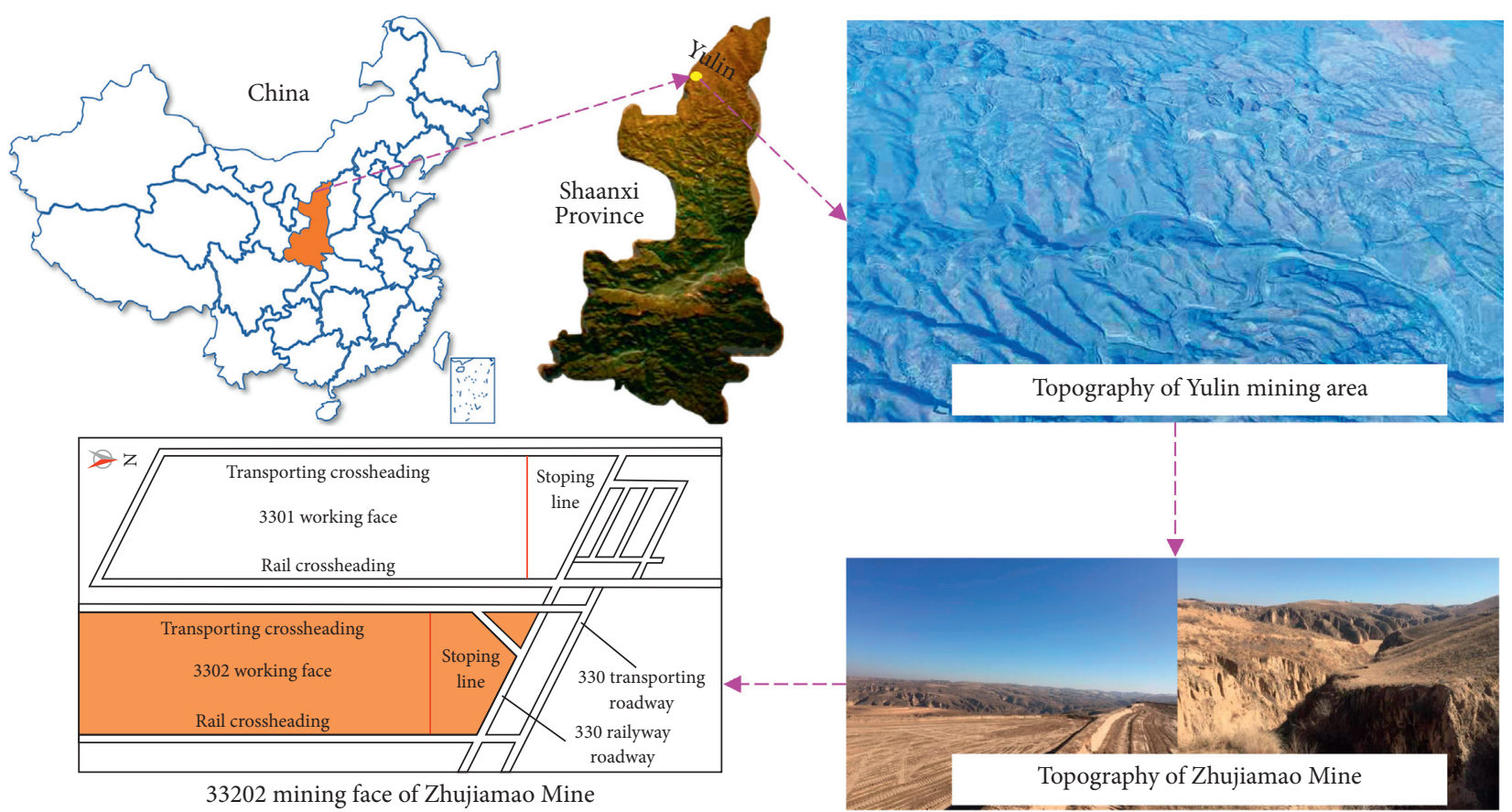

Figure 1: Study site.

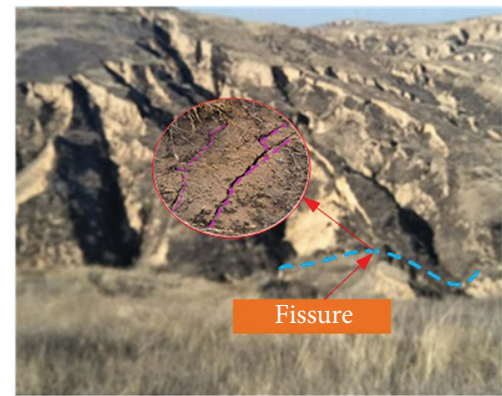

(a)

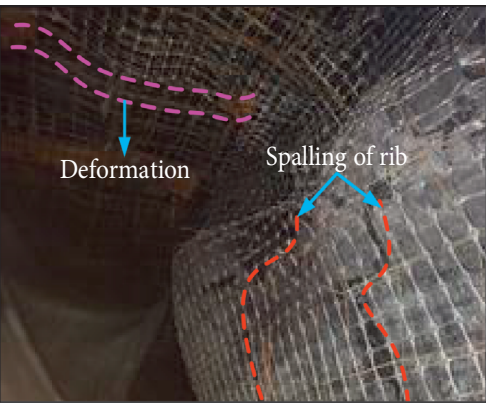

(b)

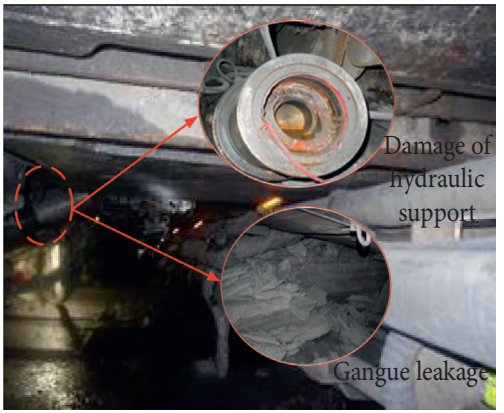

(c)

Figure 2: Macroscopic strata behaviors. (a) Ground fissures. (b) Crossheading damage. (c) Strata behaviors in face.

TABLE 1: Layout of the detection station.

\begin{tabular}{lccccccccc}
\hline Station & $1 \#$ & $2 \#$ & $3 \#$ & $4 \#$ & $5 \#$ & $6 \#$ & $7 \#$ & $8 \#$ & $9 \#$ \\
\hline Hydraulic support & $0 \#$ & $5 \#$ & $10 \#$ & $15 \#$ & $20 \#$ & $25 \#$ & $30 \#$ & $35 \#$ & $40 \#$ \\
Station & $11 \#$ & $12 \#$ & $13 \#$ & $14 \#$ & $15 \#$ & $16 \#$ & $17 \#$ & $18 \#$ & $19 \#$ \\
Hydraulic support & $50 \#$ & $55 \#$ & $60 \#$ & $65 \#$ & $70 \#$ & $75 \#$ & $80 \#$ & $85 \#$ & $90 \#$ \\
Station & $21 \#$ & $22 \#$ & $23 \#$ & $24 \#$ & $25 \#$ & $26 \#$ & $27 \#$ & $28 \#$ & $29 \#$ \\
Hydraulic support & $100 \#$ & $105 \#$ & $110 \#$ & $115 \#$ & $120 \#$ & $125 \#$ & $130 \#$ & $135 \#$ & $140 \#$ \\
\hline
\end{tabular}

form the lower section. The upper section is arranged to close the transporting crossheading, and the lower section is close to the rail crossheading. The detecting range is $60 \mathrm{~m}$ before and after the gully bottom; that is, the detecting starts at $60 \mathrm{~m}$ in front of the gully bottom and ends at $60 \mathrm{~m}$ behind the gully bottom.

As presented in Figure 4, the working resistance curves of typical hydraulic supports in the upper, middle, and lower sections are plotted, respectively. Along the inclining direction, the working resistance of the hydraulic support in the middle section is significantly greater than that in the upper and lower sections. Obviously, there is a support pressure arch in the inclined direction of the mining face, and the overburden in the pressure arch collapses under the action of its own weight, which forms the pressure on the support. The subsidence of the roof overburden in the 


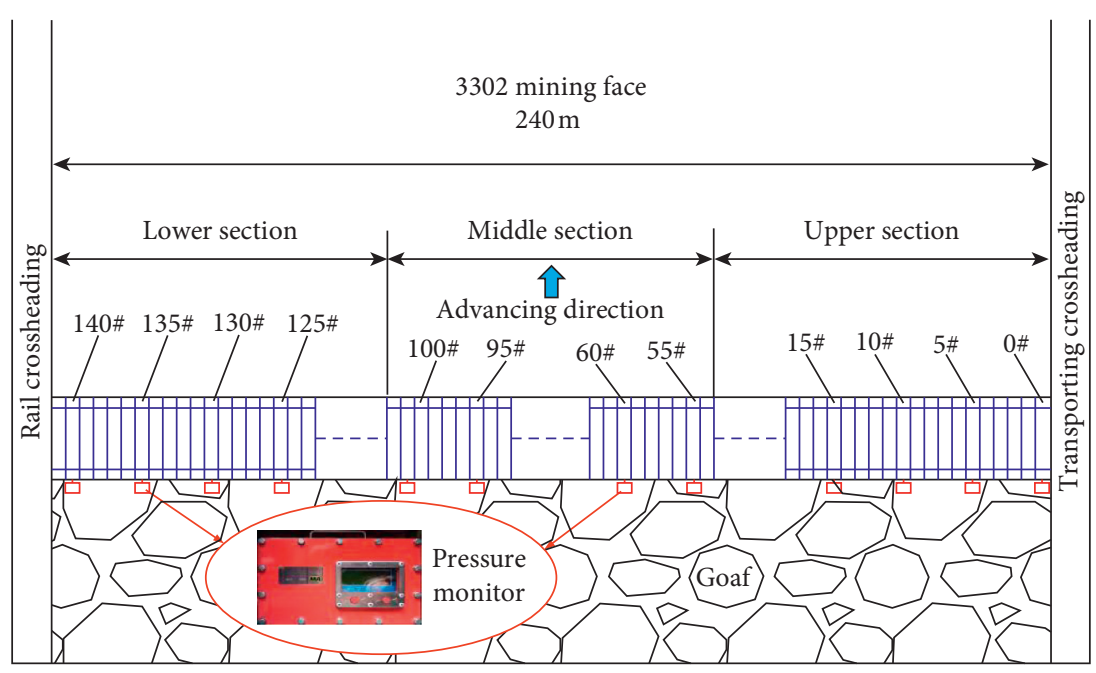

Figure 3: Layout of the detection station.

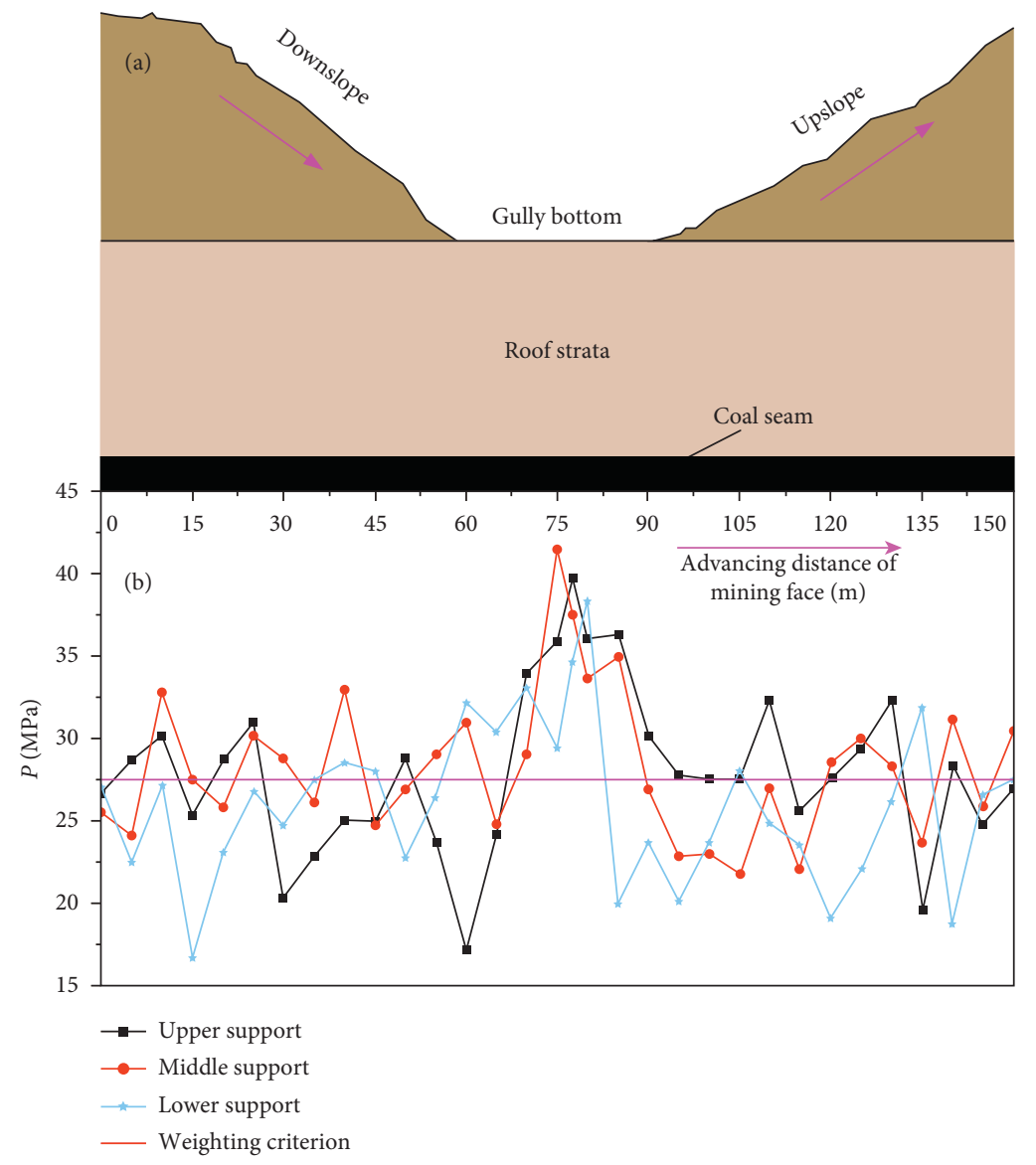

FIGURE 4: Working resistance of face support.

middle of the pressure arch is the largest, which makes the management of the middle of the roof the most difficult, so the working resistance of the support is the highest. Along the advancing direction of the face, the working resistance of the support beneath the gully bottom is the highest in all three detecting sections. The working resistance of the support is low and changes smoothly during mining beneath the downslope and upslope sections. However, the working resistance rises sharply due to the impact of dynamic load during mining beneath the gully bottom. The maximum working resistances of the upper, middle, and lower sections all appear beneath the gully bottom; the values are $39.7 \mathrm{MPa}$, 
41.5 $\mathrm{MPa}$, and 38.4 MPa, respectively, which are increased by $44.36 \%, 31.75 \%$, and $16.36 \%$ compared with the previous peak working resistance, and the dynamic load coefficients are $1.44,1.51$, and 1.40 .

Through the above analysis, it can be concluded that the laws on working resistance of hydraulic support are consistent with those on macroscopic strata behaviors. The dynamic strata behaviors are the strongest beneath the gully bottom, which indicates that the strata behaviors are affected by the gully terrain obviously.

\section{Theoretical Analysis}

The mechanism of strong dynamic strata behaviors in the face during mining beneath the gully terrain is studied systematically by experts and scholars [43]. Figure 5 presents the reasons for different strata behaviors in the face during mining beneath different terrain attitudes vividly [43]. As presented in Figure 5(a), during mining beneath the downslope section, the rock beam at the end extending into the coal wall will not be broken due to the lateral restriction of the broken block at the back when the key stratum of the overlying rock is rotated and sunk, so that there will be no strong strata behaviors caused by dynamic load impact.

However, as presented in Figure 5(b), during mining beneath the gully bottom, the thickness of overlying strata on the face decreases gradually, which makes the load on the key stratum of overlying strata non-uniform. With the continuous advancing of the mining face, the hanging distance of the roof gradually increases, and the key stratum bends and rotates as well. When the hanging distance of the roof reaches the limit, the key stratum also reaches the bearing limit of the non-uniform load as well, which makes it break. The rotation of the broken block A makes block B unable to be subjected to horizontal force and friction force, so that block B slips and breaks, resulting in severe strata pressure, which is the fundamental reason for the dynamic strata behaviors during mining beneath the gully bottom.

\section{Numerical Simulation}

Based on the above research, in order to further explore the influence of gully terrain on the strata behaviors laws for shallow coal seam mining, UDEC is applied to carry out the numerical simulation for mining beneath gully terrain.

5.1. Numerical Model. According to the geological conditions of 3302 face in Zhujiamao Coal Mine, the coal seam and overlying strata of this face are selected as the numerical prototype. As presented in Figure 6, on the basis of the simplified geological conditions, the two-dimensional numerical model is established. Several trapezoids are established on the surface at the top of the model to approximately represent the gully terrain, which can more comprehensively study the influence of strata behaviors during mining beneath gully terrain in shallow coal seam. The length of the model is $320 \mathrm{~m}$, the highest point height of the overlying strata is $223 \mathrm{~m}$, and the lowest height is $173 \mathrm{~m}$. The top of the model is set as a free boundary, and boundary constraints are applied to both sides and bottoms of the model. The density of the block elements in the model is adjusted according to the rock mechanical strength characteristics and joint distribution of each stratum, which makes it similar to the distribution characteristics of the actual rock mass. The mechanical parameters of strata applied in the model are presented in Table 2. In the simulation, the deformed material is separated into discrete block sets to represent the discontinuous medium. And the Mohr-Coulomb model is used in the simulation.

\subsection{Analysis on the Laws of Overburden Movement and Fissure} Development. The movement of overlying strata and the development of fissures are affected obviously by the attitude of terrain during mining beneath the gully terrain. The overlying strata movement and fracture development affected by mining are varying due to the different attitudes of terrain. Under different excavation lengths of mining face, the simulation results of overburden movement and fracture development are presented in Figure 7. In Figure 7, the cloud image on the left presents the overall movement of overburden, and the images on the right present the development of fissures and the local enlargement of overburden movement beneath the corresponding terrain attitude. The movement breaking degree of overlying strata is mainly in the form of fissures, which include longitudinal cutting fissures and transverse separated fissures. According to the simulation results, the overlying strata movement and fissures development are divided into three stages:

Stage I: stage of fissures developing slowly.

When the mining face is advanced to $30 \mathrm{~m}$, the immediate roof collapses completely, and the transverse fissures with inconspicuous development are generated in the main roof synchronously. When the mining face is advanced to $38 \mathrm{~m}$, the initial weighting causes the breaking and collapse of main roof. Additionally, the overburden begins to bend and sink, and the fissures continue to develop upwards. Affected by the size effect, the development of fissures is slow and slight within the range of $38 \mathrm{~m}$.

Stage II: stage of fissures developing rapidly.

With the continuous mining of face, the movement range of overburden is gradually expanded, and the development speed and degree of fissures are improved significantly as well. When the working face is advanced to $70 \mathrm{~m}$, the deformation of the overlying strata aggravates obviously with the complete breaking and collapsing of main roof. Additionally, the gangue collapsing in the goaf is compacted gradually at this period. When the face is mined from $70 \mathrm{~m}$ to $200 \mathrm{~m}$, the surface sinks gradually due to the effect of the overburden movement. Furthermore, the main roof breaks periodically with decreasing weighting step and increasing weighting strength. At the same time, with the continuous collapsing of the overlying strata, the fissures generated by mining also 


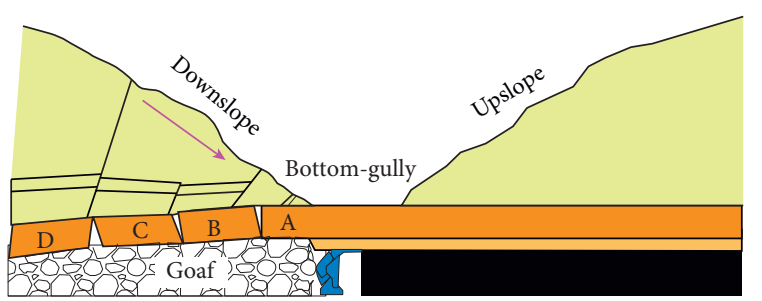

(a)

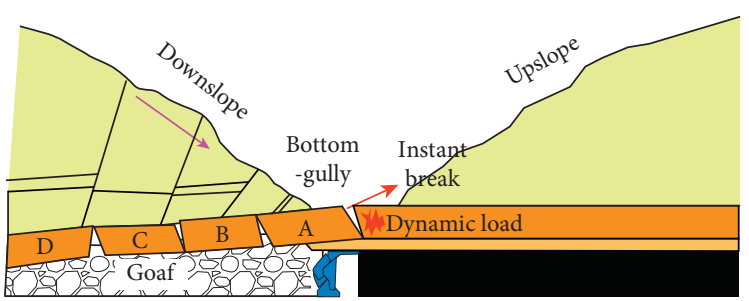

(b)

Figure 5: Mechanism of dynamic strata behaviors. (a) Mining beneath downslope section. (b) Mining beneath gully bottom.

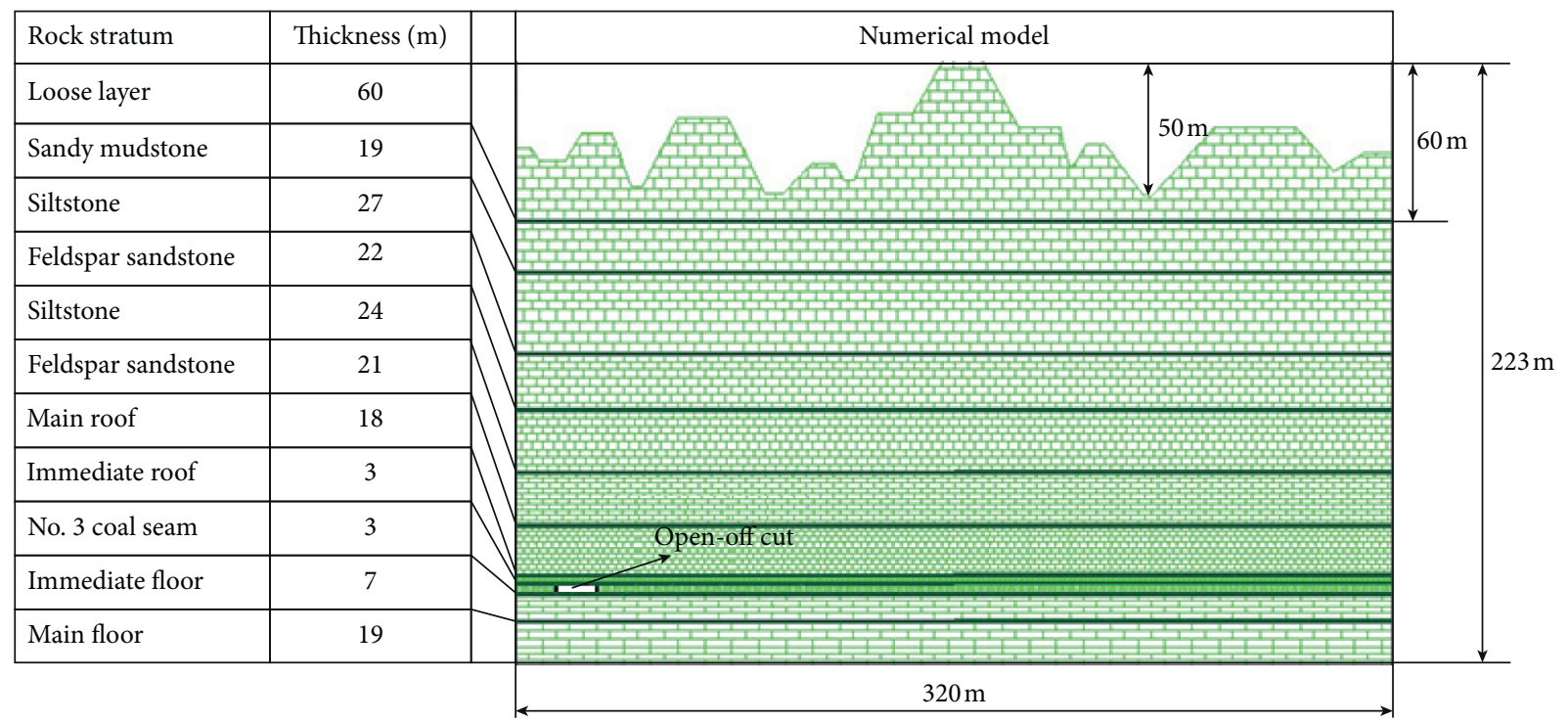

Figure 6: Numerical model.

TABLE 2: Mechanical parameters of strata.

\begin{tabular}{|c|c|c|c|c|c|c|c|}
\hline Rock stratum & $\begin{array}{c}\text { Thickness } \\
(\mathrm{m})\end{array}$ & $\begin{array}{c}\text { Density } \\
\left(\mathrm{kg} \cdot \mathrm{m}^{-3}\right)\end{array}$ & $\begin{array}{c}\text { Bulk modulus } \\
(\mathrm{GPa})\end{array}$ & $\begin{array}{c}\text { Shear modulus } \\
(\mathrm{GPa})\end{array}$ & $\begin{array}{c}\text { Cohesion } \\
(\mathrm{MPa})\end{array}$ & $\begin{array}{c}\text { Internal friction } \\
\text { angle }\left({ }^{\circ}\right)\end{array}$ & $\begin{array}{c}\text { Tensile strength } \\
(\mathrm{MPa})\end{array}$ \\
\hline Loose layer & 60 & 2000 & & & & & \\
\hline $\begin{array}{l}\text { Sandy } \\
\text { mudstone }\end{array}$ & 19 & 2450 & 2.3 & 2.1 & 1.8 & 32 & 1.3 \\
\hline Siltstone & 27 & 2550 & 3.4 & 3.1 & 2.6 & 31 & 1.4 \\
\hline $\begin{array}{l}\text { Feldspar } \\
\text { sandstone }\end{array}$ & 22 & 2500 & 3.1 & 3.0 & 2.5 & 30 & 1.1 \\
\hline Siltstone & 24 & 2550 & 3.4 & 3.1 & 2.6 & 31 & 1.4 \\
\hline $\begin{array}{l}\text { Feldspar } \\
\text { sandstone }\end{array}$ & 21 & 2500 & 3.1 & 3.0 & 2.5 & 30 & 1.1 \\
\hline Siltstone & 18 & 2450 & 2.3 & 2.1 & 1.7 & 29 & 0.6 \\
\hline $\begin{array}{l}\text { Feldspar } \\
\text { sandstone }\end{array}$ & 3 & 2550 & 3.4 & 3.1 & 2.6 & 31 & 1.4 \\
\hline No. 3 coal seam & 3 & 1333 & 2.5 & 2.3 & 0.4 & 29 & 0.7 \\
\hline Siltstone & 7 & 2550 & 3.3 & 3.0 & 2.7 & 31 & 1.4 \\
\hline $\begin{array}{l}\text { Feldspar } \\
\text { sandstone }\end{array}$ & 19 & 2500 & 3.2 & 3.1 & 2.6 & 32 & 1.1 \\
\hline
\end{tabular}

continue to be compacted in the middle of the goaf, resulting in the compaction area. With the continuous advancement of working face, the scope of compaction area is also expanding. Within the mining range of $38 \mathrm{~m}$ to $200 \mathrm{~m}$, the fissure development degree of overlying strata increases significantly, and the fissure development height increases rapidly as well. In this stage, the fissures are mainly longitudinal fissures 


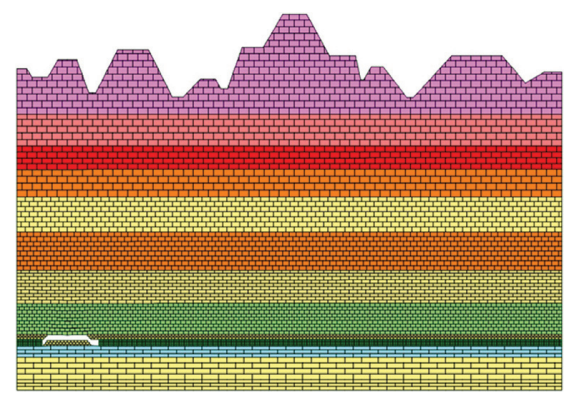

(a)

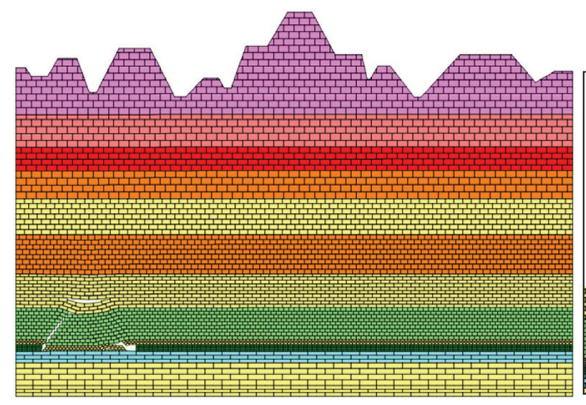

(c)

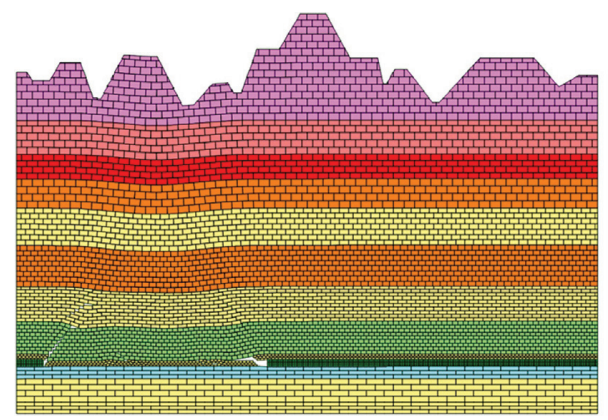

(e)

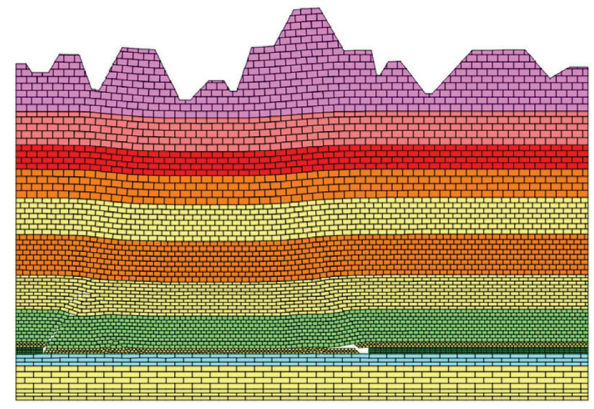

(g)
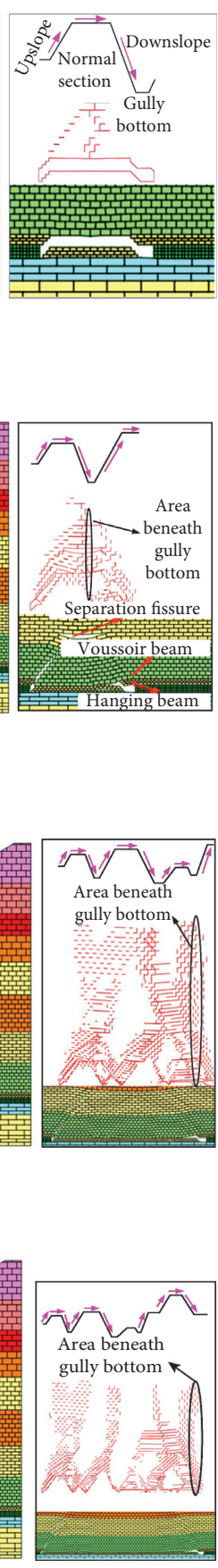

Figure 7: Laws of overburden movement and fissure development. (a) $30 \mathrm{~m}$. (b) $38 \mathrm{~m}$. (c) $70 \mathrm{~m}$. (d) $110 \mathrm{~m}$. (e) $140 \mathrm{~m}$. (f) $170 \mathrm{~m}$. (g) $200 \mathrm{~m}$. (h) $240 \mathrm{~m}$.

beneath the gully bottom. Evidently, the development height and speed of fissures are more obvious during mining beneath the gully bottom than those during other areas.

Stage III: stage of fissures developing stably.

When the working face is mined from $200 \mathrm{~m}$ to $280 \mathrm{~m}$, the overburden movement tends to be stable gradually

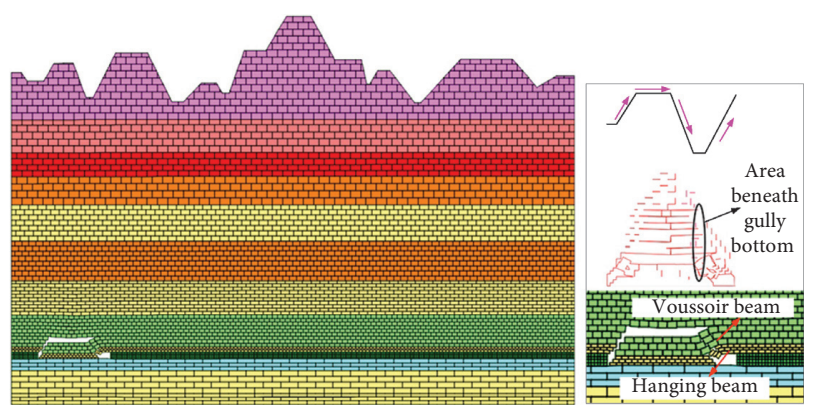

(b)

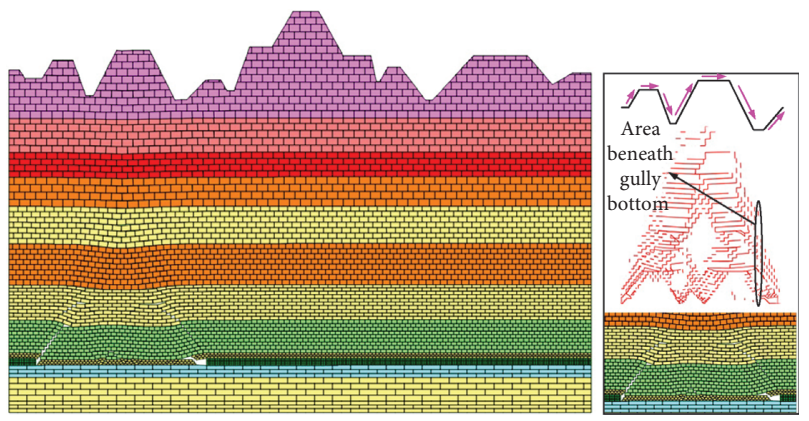

(d)

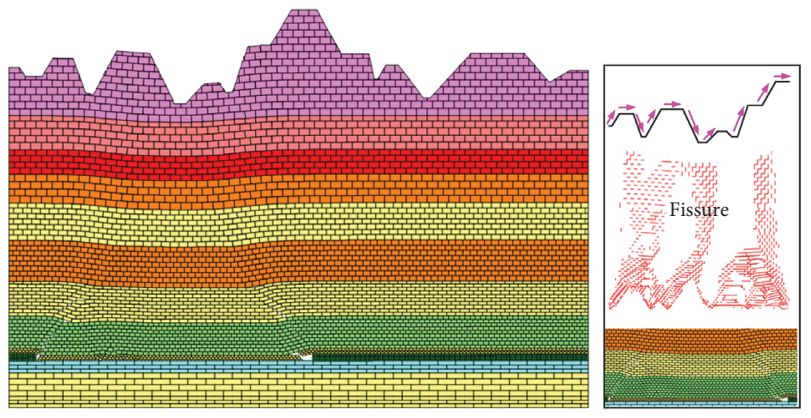

(f)

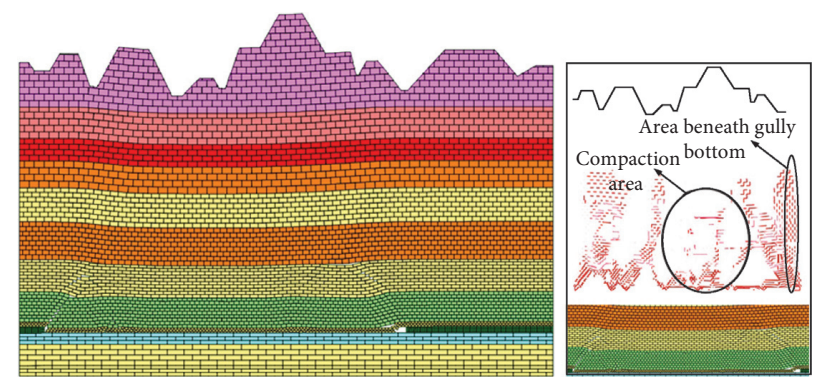

(h) and the periodic weighting basically returns to normal. Synchronously, the fissures begin to close gradually, and the fissures height basically does not change after the fissure development is in a stable state. Additionally, the collapsing gangue in the goaf is still compacted continuously, but the compaction degree is different due to the different compaction time. The fissures close to the coal wall is light, while 
the middle of the goaf has been compacted completely, which indicates that there is a "space-time relationship" between the overlying strata fissures and the face.

With the different advancing distance of mining face, the movement degree of roof overburden and the development law of fissures change as well. However, although the advancing distance is different, the fissures are dominated by longitudinal fissures and the degree of fissures development is obviously improved during mining beneath gully bottom, which fully indicates that the strong dynamic strata behaviors are caused by the breaking of the key stratum.

5.3. Analysis on the Laws of Overburden Stress and Displacement. The stress and subsidence of the main roof show different evolution laws with the different face advancing distance. Meanwhile, the stress and subsidence of the main roof are affected by the attitudes as well during mining beneath gully terrain. The evolution curves of stress and subsidence for main roof under different advancing distances are presented in Figure 8.

The evolution of stress is analyzed firstly. After the coal seam is mined, the stress on the roof of the goaf is released, resulting in the stress reduction zone in the corresponding position of the goaf. Generally speaking, the range of stress reduction area gradually increases with the increase of the mining range, and gully terrain has local influence on the stress evolution. As presented in Figure 8(a), when the mining face is advanced to $30 \mathrm{~m}$, the stress in the middle of the face is the smallest. Concurrently, the stress in front of the face is slightly greater than that behind the face due to the influence of advance abutment pressure. As presented in Figure 8(b), when the face is advanced to $38 \mathrm{~m}$, the stress rebounds slightly beneath the gully bottom (the range of 46 50 $\mathrm{m}$ along the strike in the numerical model) and then drops rapidly after passing through this gully bottom.

As presented in Figure $8(\mathrm{c})$, when the mining face is advanced to $70 \mathrm{~m}$, the stress beneath the top of the slope is the largest, which is caused by the increase of the load on the roof overburden due to the thick overlying topsoil. As presented in Figure 8(d), when the mining face is advanced to $110 \mathrm{~m}$, the stress rebounds beneath the both gully bottoms (the range of $96 \sim 100 \mathrm{~m}$ and $121 \sim 124 \mathrm{~m}$ along the strike in the numerical model). Furthermore, the stress near the coal wall is greater than that behind the face due to the influence of the advance abutment pressure. As presented in Figure 8(e), when the mining face is advanced to $140 \mathrm{~m}$, the stress decreases symmetrically from the open-off cut and coal wall to the middle of the face. However, there is still stress concentration at the gully bottom within the range of $46 \sim 50 \mathrm{~m}$ along the strike, which is due to the dynamic load impact caused by the breaking of the key stratum again at this position as the face continues to advance. As presented in Figure 8(f), when the working face is advanced to $170 \mathrm{~m}$, the stress in the middle of the face is the lowest, and the stress on both sides rises symmetrically. As presented in Figure $8(\mathrm{~g})$, when the face is advanced to $200 \mathrm{~m}$, the stress rebounds beneath the gully bottom (the range of $200 \sim 202 \mathrm{~m}$ along the strike in the numerical model), and then the stress decreases gradually as the face passes through the gully bottom. As presented in Figure 8(h), when the face is advanced to $240 \mathrm{~m}$, the stress beneath the gully bottom (the range of 228 231 $\mathrm{m}$ along the strike in the numerical model) rises rapidly under the impact of dynamic load, resulting in high-strength stress concentration. Since the advance of the follow-up face no longer passes through the gully bottoms, the advance of the follow-up face is no longer studied.

The evolution of subsidence is analyzed as well. Collectively, with the increase of mining length, the maximum roof subsidence increases gradually. As presented in Figure 8 , in the range of mining length from $30 \mathrm{~m}$ to $240 \mathrm{~m}$, the maximum roof subsidence is $0.28 \mathrm{~m}, 0.58 \mathrm{~m}, 1.74 \mathrm{~m}, 2.52 \mathrm{~m}$, $2.79 \mathrm{~m}, 2.82 \mathrm{~m}, 2.95 \mathrm{~m}$, and $2.97 \mathrm{~m}$, respectively. It can be found that the change rate of roof subsidence decreases gradually and the roof subsidence tends to be stable when the advancing length of the face is more than $140 \mathrm{~m}$. When the mining length is more than $200 \mathrm{~m}$, a subsidence basin is formed at the top of the model, and the maximum subsidence does not increase with the increase of mining length. Additionally, the attitude of gully terrain has an effect on the subsidence of roof. The roof subsidence is slightly larger than that of the adjacent position during mining beneath the gully bottom, which indicates that the dynamic load generated at the gully bottom promotes the roof subsidence.

Based on the above analysis, the stress and subsidence of overlying strata are obviously affected by gully terrain. The dynamic load impact caused by the rotation and breaking of the key stratum results in the increase of the roof stress and subsidence during mining beneath the gully bottom. The numerical simulation results are in accordance with the field detection and theoretical analysis results, which verify the reliability of the results.

\section{Discussion}

The above research shows that the gully terrain has a great influence on the strata behaviors of shallow seam mining. The dynamic load impact is produced due to the rotation and breaking of the key stratum during mining beneath the gully bottom, resulting in severe strata behaviors. In order to effectively avoid the influence of dynamic strata behaviors during mining beneath the gully bottom, the following prevention measures are proposed.

(1) Strengthening the monitoring and forecasting of strata pressure.

The working resistance of hydraulic support should be monitored in real time to accurately predict the strata behaviors laws of face during mining beneath the gully bottom. More importantly, effective preventive measures should be taken in time according to the monitoring results.

(2) Shortening the length of mining face.

The length of mining face is closely related to strata behaviors. The longer the face is, the stronger the strata behaviors are. If the strata behaviors are 


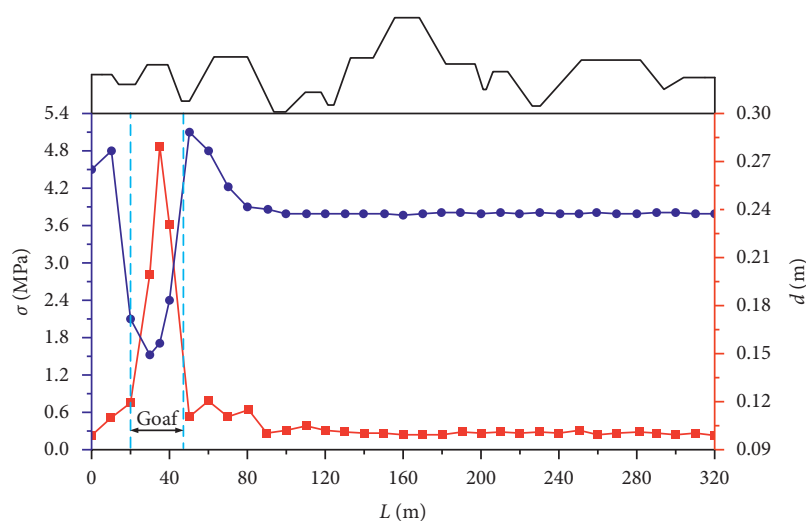

$\because$ Stress
$\because$ Displacement

(a)

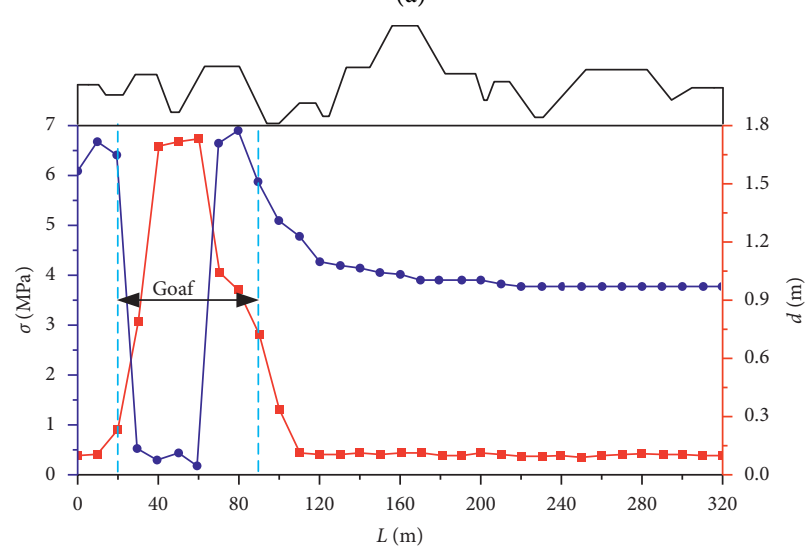

$\longrightarrow$ Stress

— Displacement

(c)

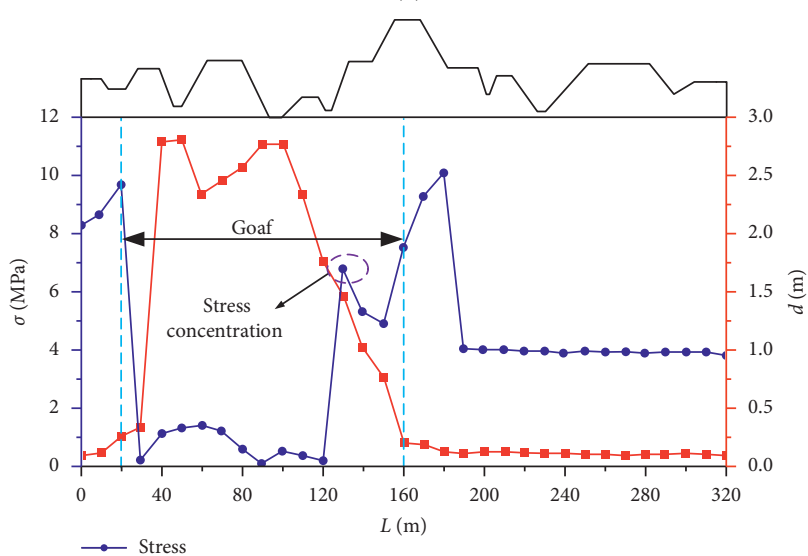

$\because$ Stress
$\because$ Displacement

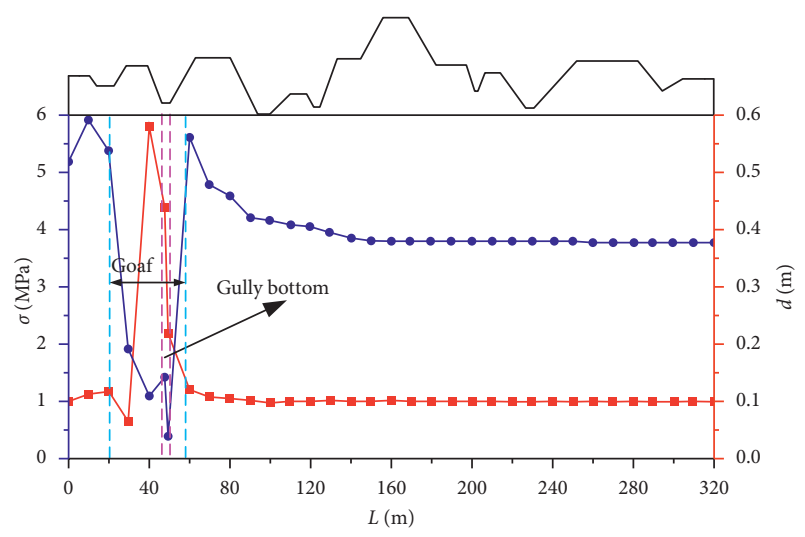

$\because$ Stress
$\because$ Displacement

(b)

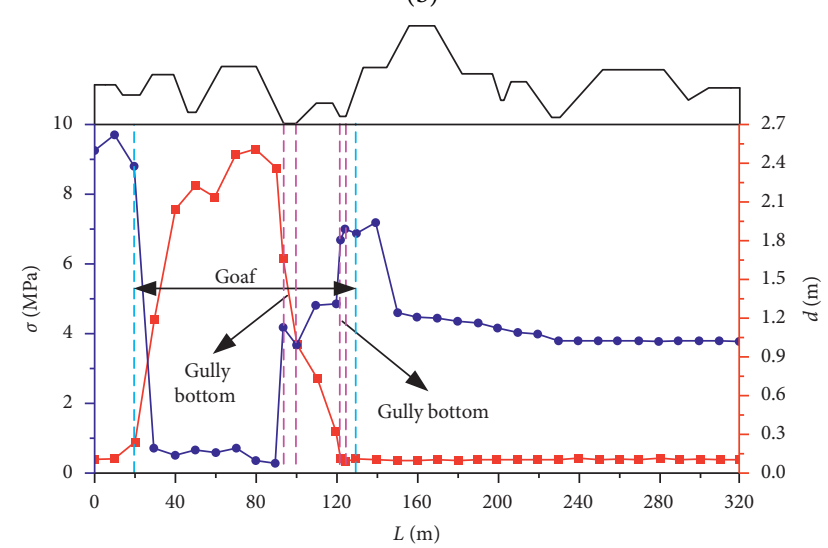

- Stress

$\longrightarrow$ Displacement

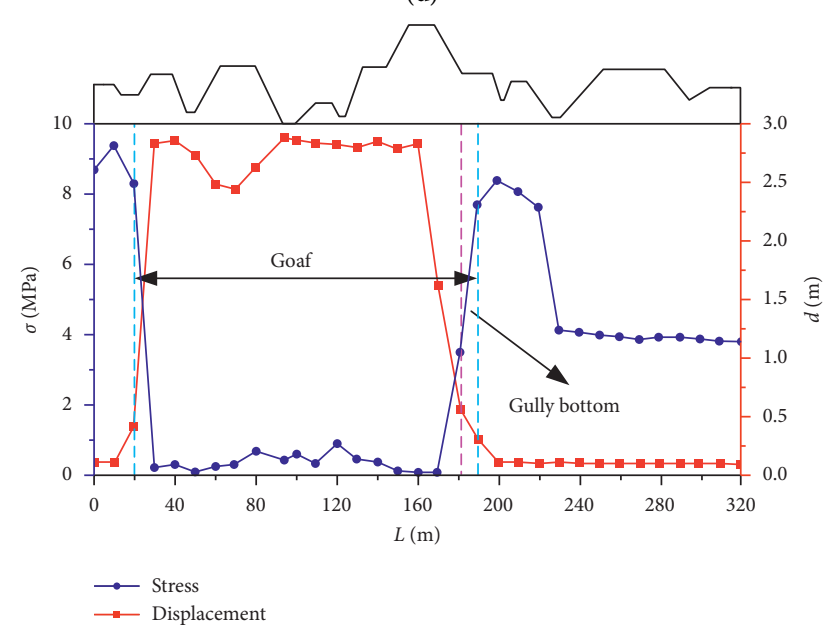

(e)

(f)

Figure 8: Continued. 


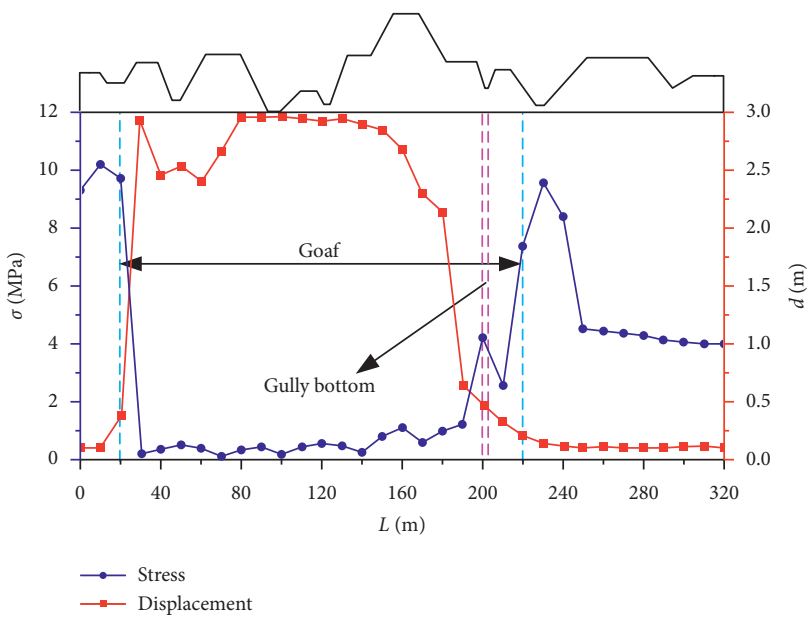

(g)

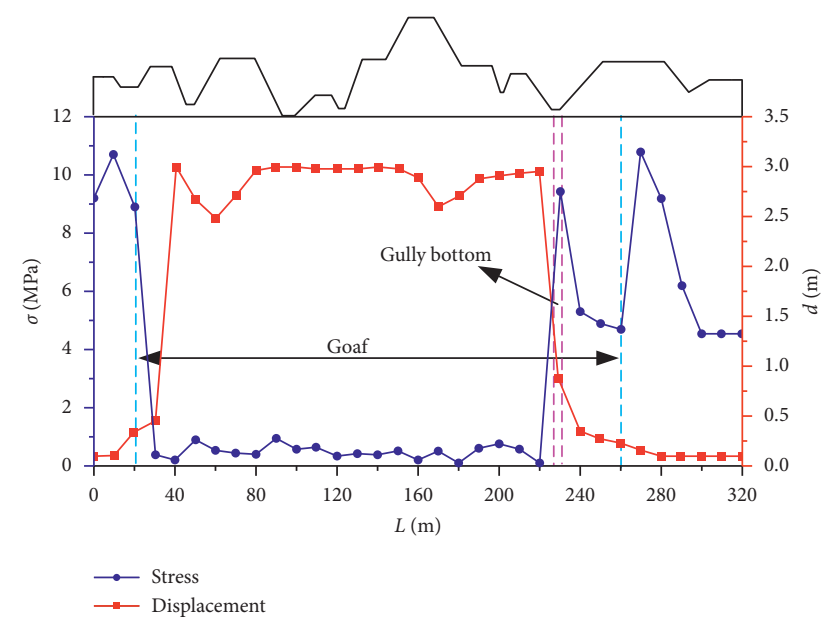

(h)

Figure 8: Laws of overburden movement and fissure development. (a) $30 \mathrm{~m}$. (b) $38 \mathrm{~m}$. (c) $70 \mathrm{~m}$. (d) $110 \mathrm{~m}$. (e) $140 \mathrm{~m}$. (f) $170 \mathrm{~m}$. (g) $200 \mathrm{~m}$. (h) $240 \mathrm{~m}$.

severe during mining beneath the gully bottom, the mining face should be shortened in time to improve the advancing speed, which can slow down the movement of overlying strata and make the face pass through the area affected by dynamic load quickly.

(3) Reducing the mining height of face.

The greater the thickness of the coal seam mined at one time, the greater the roof subsidence, which leads to the greater difficulty of roof management. If the strata behaviors are severe during mining beneath the gully bottom, the appropriate reduction of the mining height of the face can reduce the collapsing space of the overlying strata, which is conducive to the formation of a more stable masonry beam structure on the main roof, thus reducing the failure degree of the overlying strata.

(4) Selecting hydraulic supports with strong working resistance.

After the coal seam is mined out, the static load produced by the subsidence of roof overburden acts on the hydraulic support. Under the longterm action of high static load, once the hydraulic support is impacted by dynamic load, it is easy to lose stability and damage. In order to effectively resist the impact of dynamic load caused by the breaking of key strata during mining beneath the gully bottom, it is necessary to select hydraulic support with strong working resistance.

\section{Conclusions}

Taking 3302 mining face of Zhujiamao Coal Mine as the engineering background, the methods of field detection, theoretical analysis, and numerical simulation are applied to study the laws of strata behaviors for shallow coal seam mining beneath gully terrain. Compared with current published works, this paper highlights three important messages:

(1) The strata pressure observation and the hydraulic support working resistance detection are carried out in the field, and it is concluded that the strata behaviors are the strongest during mining beneath the gully bottom.

(2) The mechanism of strata behaviors for shallow coal seam mining beneath gully terrain is analyzed theoretically. It is considered that the rotation and breaking of key stratum beneath gully bottom under non-uniform load is the fundamental cause of strong dynamic strata behaviors.

(3) Numerical experiment is applied to simulate the overburden movement and fissure development characteristics for shallow coal seam mining beneath gully terrain. Furthermore, the evolution laws of roof stress and subsidence are analyzed. The simulation results show that the strata behaviors beneath the gully bottom are stronger than those beneath other areas.

Additionally, according to the laws of dynamic strata behaviors for shallow coal seam mining beneath gully terrain, the safety measures are put forward.

The findings of this study are beneficial for a better understanding of strata behaviors for shallow coal seam mining beneath gully terrain. This strategy provides sufficient details to allow its application in other coal mines.

\section{Data Availability}

The data used to support the findings of this study are available from the corresponding author upon request. 


\section{Conflicts of Interest}

The authors declare no conflicts of interest.

\section{Acknowledgments}

This work was supported by the National Natural Science Foundation of Surface Project of China (Nos. 51774289 and 52074291), the National Natural Science Foundation of the Youth Science Foundation of China (No. 51404270), and the Open Fund of State Key Laboratory of Green and Safe Development of Western Coal (SKLCRKF1903).

\section{References}

[1] Q. Huang, J. Du, J. Chen, and Y. He, "Coupling control on pillar stress concentration and surface cracks in shallow multiseam mining," International Journal of Mining Science and Technology, vol. 31, no. 1, pp. 95-101, 2021.

[2] C. Zhao, D. Jin, J. Geng, and Q. Sun, "Numerical simulation of the groundwater system for mining shallow buried coal seams in the ecologically fragile areas of western China," Mine Water and the Environment, vol. 38, no. 1, pp. 158-165, 2019.

[3] Q. H. Li, J. K. Li, J. P. Zhang et al., "Numerical simulation analysis of new steel sets used for roadway support in coal mines," Metals, vol. 9, no. 5, pp. 1-19, 2019.

[4] X. Su, F. Zhou, and S. Tyson, "Numerical investigation of the potential contamination of a shallow aquifer in producing coalbed methane," Energy Exploration \& Exploitation, vol. 36, no. 2, pp. 282-296, 2018.

[5] J. Zuo, M. Yu, C. Li, Y. Sun, S. Hu, and Z. Li, "Analysis of surface cracking and fracture behavior of a single thick main roof based on similar model experiments in western coal mine, China," Natural Resources Research, vol. 30, no. 1, pp. 657-680, 2021.

[6] H. Liu, T. T. Zhou, X. Liu, K. Z. Deng, and S. G. Lei, "Factors that trigger the development of mining-induced ground fissures, and standards to treat them in shallow coal mining areas," Journal of the South African Institute of Mining and Metallurgy, vol. 119, no. 11, pp. 919-928, 2019.

[7] X. Wang and F.-b. Meng, "Statistical analysis of large accidents in China's coal mines in 2016," Natural Hazards, vol. 92, no. 1, pp. 311-325, 2018.

[8] X. P. Zhang, Y. J. Jiang, G. Wang, Y. Cai, and T. Iura, "Threedimensional seismic performance of mountain tunnel with imperfect interface considering $\mathrm{P}$ wave," Tunnelling and Underground Space Technology, vol. 108, pp. 1-12, 2021.

[9] T. Li, G. B. Chen, Z. C. Qin, Q. H. Li, B. Cao, and Y. L. Liu, "The gob-side entry retaining with the high-water filling material in Xin'an Coal Mine," Geomechanics and Engineering, vol. 22, no. 6, pp. 541-552, 2020.

[10] Z. Q. Wang, P. Wang, L. Shi et al., "Research on prevention of rock burst based on stress analysis of surrounding rock of gob-side entry," Journal of China University of Mining \& Technology, vol. 49, no. 6, pp. 1046-1056, 2020.

[11] Z. Q. Wang, P. F. Li, L. Wang, Y. Gao, X. F. Guo, and C. F. Chen, "Method of division and engineering use of "three band" in the stope again," Journal of China Coal Society, vol. 38, no. S2, pp. 287-293, 2013.

[12] X. Zhang, Y. Jiang, G. Wang et al., "Mechanism of shear deformation, failure and energy dissipation of artificial rock joint in terms of physical and numerical consideration," Geosciences Journal, vol. 23, no. 3, pp. 519-529, 2018.
[13] X. Wang, Z. Wen, Y. Jiang, and H. Huang, "Experimental study on mechanical and acoustic emission characteristics of rock-like material under non-uniformly distributed loads," Rock Mechanics and Rock Engineering, vol. 51, no. 3, pp. 729-745, 2018.

[14] H. G. Xiao, L. He, J. C. Li, C. J. Zou, and C. M. Chao, "Permeability prediction for porous sandstone using digital twin modeling technology and Lattice Boltzmann method," International Journal of Rock Mechanics and Mining Sciences, vol. 142, pp. 1-11, 2021.

[15] J. Ju, J. Xu, and W. Zhu, "Longwall chock sudden closure incident below coal pillar of adjacent upper mined coal seam under shallow cover in the Shendong coalfield," International Journal of Rock Mechanics and Mining Sciences, vol. 77, pp. 192-201, 2015.

[16] F. Wang, J. Xu, and J. Xie, "Effects of arch structure in unconsolidated layers on fracture and failure of overlying strata," International Journal of Rock Mechanics and Mining Sciences, vol. 114, pp. 141-152, 2019.

[17] F. Wang, J. Xu, S. Chen, and M. Ren, "Method to predict the height of the water conducting fractured zone based on bearing structures in the overlying strata," Mine Water and the Environment, vol. 38, no. 4, pp. 767-779, 2019.

[18] C. Zhang, S. Tu, L. Zhang, Q. Bai, Y. Yuan, and F. Wang, “A methodology for determining the evolution law of gob permeability and its distributions in longwall coal mines," Journal of Geophysics and Engineering, vol. 13, no. 2, pp. 181-193, 2016.

[19] G. H. McNally, "Geology and mining practice in relation to shallow subsidence in the northern coalfield, new south wales," Australian Journal of Earth Sciences, vol. 47, no. 1, pp. 21-34, 2000.

[20] S. Kedzior, "The occurrence of a secondary zone of coal-bed methane in the southern part of the upper silesian coal basin (Southern Poland): potential for methane exploitation," International Journal of Coal Geology, vol. 86, no. 2-3, pp. 157-168, 2011.

[21] A. J. Das, P. K. Mandal, A. Prakash, L. B. Roy, and S. Tewari, "Underground extraction methodology of contiguous coal seams ensuring the safety of the parting and the surface structures," Safety Science, vol. 121, pp. 215-230, 2020.

[22] C. Wang, C. Zhang, X. Zhao, L. Liao, and S. Zhang, "Dynamic structural evolution of overlying strata during shallow coal seam longwall mining," International Journal of Rock Mechanics and Mining Sciences, vol. 103, pp. 20-32, 2018.

[23] Q. Huang, "Experimental research of overburden movement and subsurface water seeping in shallow seam mining," Journal of University of Science and Technology Beijing, Mineral, Metallurgy, Material, vol. 14, no. 6, pp. 483-489, 2007.

[24] Y. Liu, S. C. Yuan, B. B. Yang, J. W. Liu, and Z. Y. Ye, "Predicting the height of the water-conducting fractured zone using multiple regression analysis and GIS," Environmental Earth Sciences, vol. 78, no. 14, pp. 1-15, 2019.

[25] X.-J. Cheng, H. Wen, Y.-H. Xu, S.-X. Fan, and S.-J. Ren, "Environmental treatment technology for complex coalfield fire zone in a close distance coal seam-a case study," Journal of Thermal Analysis and Calorimetry, vol. 144, no. 2, pp. 563574, 2021.

[26] W. Wang and Y. Liang, "Prevention and control technology for harmful toxic gas intrusion in high-fire-hazard-risk areas of close-distance coal seams," Journal of Chemistry, vol. 2020, Article ID 9040825, 12 pages, 2020. 
[27] J. Z. Li, Z. H. Jiao, M. Zhang, and Y. Li, "Dynamic evolution characteristics and mechanism of surrounding rock fractures during the repeated mining of closed distance deep coal seam," Revista Internacional de Contaminación Ambiental, vol. 35, no. S1, pp. 165-176, 2019.

[28] H. Shang, J. Ning, S. Hu, S. Yang, and P. Qiu, "Field and numerical investigations of gateroad system failure under an irregular residual coal pillar in close-distance coal seams," Energy Science \& Engineering, vol. 7, no. 6, pp. 2720-2740, 2019.

[29] X. Gao, S. Zhang, Y. Zi, and S. K. Pathan, "Study on optimum layout of roadway in close coal seam," Arabian Journal of Geosciences, vol. 13, no. 15, pp. 1-17, 2020.

[30] Z. Li, J. Xu, J. Ju, W. Zhu, and J. Xu, "The effects of the rotational speed of voussoir beam structures formed by key strata on the ground pressure of stopes," International Journal of Rock Mechanics and Mining Sciences, vol. 108, pp. 67-79, 2018.

[31] Q. L. Yao, T. Chen, C. J. Tang, M. Sedighi, S. W. Wang, and Q. X. Huang, "Influence of moisture on crack propagation in coal and its failure modes," Engineering Geology, vol. 258, pp. 1-12, 2019.

[32] Q. Wang, W. Li, T. Li, X. Li, and S. Liu, "Goaf water storage and utilization in arid regions of northwest China: a case study of Shennan coal mine district," Journal of Cleaner Production, vol. 202, pp. 33-44, 2018.

[33] Z. Q. Wang, X. Zhu, and L. Wang, "New method and application of three zone in mining overall height of thick coal seam in one times' working face," Journal of Liaoning Technical University, vol. 32, no. 4, pp. 454-460, 2013.

[34] J. Ning, J. Wang, Y. Tan, and Q. Xu, "Mechanical mechanism of overlying strata breaking and development of fractured zone during close-distance coal seam group mining," International Journal of Mining Science and Technology, vol. 30, no. 2, pp. 207-215, 2020.

[35] H. G. Xiao, L. He, X. Li, Q. B. Zhang, and W. G. Li, "Texture synthesis: a novel method for generating digital models with heterogeneous diversity of rock materials and its CGM verification," Computers and Geotechnics, vol. 130, pp. 1-14, 2021.

[36] J. W. Li, C. Y. Liu, W. C. Wang, and C. Y. Wang, "Linkageinduced mechanism and control technology of pressure bump and surface geological damage in shallow coal seam mining of gully area," Arabian Journal of Geosciences, vol. 12, no. 11, pp. 1-10, 2019.

[37] X. F. Wang, Y. Wang, D. S. Zhang et al., "Characteristics of strata behavior during thick seam mining by fully-mechanized top coal caving in a loess-covered gullied region," Minerals, vol. 7, no. 4, pp. 1-12, 2017.

[38] F. T. Wang, S. H. Tu, C. Zhang, Y. W. Zhang, and Q. S. Bai, "Evolution mechanism of water-flowing zones and control technology for longwall mining in shallow coal seams beneath gully topography," Environmental Earth Sciences, vol. 75, no. 19, pp. 1-16, 2016.

[39] X. F. Wang, Y. Wang, D. S. Zhang et al., "Roof instability mechanism of longwall coalface for sandy soil gullies overlaying shallow seams," Disaster Advances, vol. 6, no. S5, pp. 260-267, 2013.

[40] G. Fan, D. Zhang, S. Zhang, and C. Zhang, "Assessment and prevention of water and sand inrush associated with coal mining under a water-filled buried gully: a case study," Mine Water and the Environment, vol. 37, no. 3, pp. 565-576, 2018.

[41] Y. M. Liu, "Quantitative evaluation of ecological environmental damage caused by coal mining in Shenfu Area of
Ordos Basin," Fresenius Environmental Bulletin, vol. 30, no. 3, pp. 2566-2579, 2021.

[42] K. A. Fryirs, K. Cowley, and G. C. Hose, "Intrinsic and extrinsic controls on the geomorphic condition of upland swamps in Eastern NSW," Catena, vol. 137, pp. 100-112, 2016.

[43] J. Zhang, J. J. Long, T. Yang, B. Wang, and F. W. Zhou, "Study on dynamic loading mechanism of mining in gully area of shallow coal seam," Journal of Mining \& Safety Engineering, vol. 36, no. 6, pp. 1222-1227, 2019. 